Bangl. J. Vet. Med. (2006). 4 (2): 87-92

\title{
HISTOMORPHOLOGICAL STUDY OF THE LYMPHOID TISSUES OF BROILER CHICKENS
}

\author{
S. H. Akter*, M. Z. I. Khan, M. R. Jahan, M. R. Karim and M. R. Islam \\ Department of Anatomy and Histology, Faculty of Veterinary Science, Bangladesh Agricultural University, \\ Mymensingh-2202, Bangladesh \\ *Corresponding author's e-mail: hasinavahbau@gmail.comT
}

\begin{abstract}
Topology and histology were performed in the lymphoid tissues (thymus, bursa of Fabricius, spleen and cecal tonsils) of the fifteen 28-days-old "Kasilla" broilers by observation of H \& E stained sections in the Department of Anatomy and Histology, Faculty of Veterinary Science, Bangladesh Agricultural University, Mymensingh during the period from October to December 2005. In the present study, it was observed that the thymus was enclosed by a thin connective tissue capsule. Numerous fine septa of connective tissue originated from the capsule and divide the organ into incompletely separated lobules. Each lobule organized into a peripheral cortex and a central medulla. The population of the immunocompetent cells (lymphocytes and immunoglobulin containing plasma cells) in the cortex were denser rather than that of medulla of the thymic lobule. The bursa of Fabricius was consisting of long thick mucosal folds (plicae). Numerous follicles filled the lamina propria of each fold and each bursal follicle was composed a peripheral cortex and a central medulla. The population of the immunocompetent cells in the cortex of the bursal follicle were denser rather than that of medulla of the bursal follicle. The spleen was surrounded by a thick splenic capsule and there was a small number of trabeculi. The network of the splenic tissue was consisting of a network of reticular cells and fibers and was arranged into red pulps, which were scatteredly distributed within the white pulps. The white pulp was composed of network of reticular cells and reticular fibers within which the immunocompetent cells were diffusely distributed. It contained sheathed arteries and lymphatic nodules. The red pulp of the spleen was formed from venous sinuses and anastomosing cord of reticular cells, macrophages, lymphocytes and blood cells. Cecal tonsil was composed of four histological layers i.e. tunica mucosa, submucosa, muscularis and serosa. Their lining epithelium was simple columnar epithelium. More diffuse lymphoid tissue and unorganized lymphatic nodules were present both in the mucosa and submucosa of the cecal tonsil of broiler. The length and breadth of the thymic lobules were $629.30 \pm 118.95 \mu \mathrm{m}$ and $376.03 \pm 98.92 \mu \mathrm{m}$, bursal follicles $468.83 \pm 52.26 \mu \mathrm{m}$ and $240.70 \pm 34.19 \mu \mathrm{m}$, white pulp of the spleen $112.62 \pm 13.25 \mu \mathrm{m}$ and $89.42 \pm 12.20 \mu \mathrm{m}$, lymphatic nodules of the cecal tonsil $255.20 \pm 20.46 \mu \mathrm{m}$ and $186.08 \pm$ $24.90 \mu \mathrm{m}$ respectively. The result of the present study revealed that the immunocompetent cells were arranged scatteredly or densely and as unorganized or organized lymphatic nodules in the lymphoid tissues and the length and breadth of the thymic lobule, bursal follicle, splenic white pulp and lymphatic nodule of cecal tonsils were varied within the lymphoid tissues and even one another.
\end{abstract}

Key words: Histology, lymphoid tissues, immunocompetent cells, broilers

\section{INTRODUCTION}

It is well known that, the lymphoid tissue plays an important role in the defense against microorganisms. The chicken has central (thymus and bursa of Fabricius) and peripheral (spleen and all mucosa associated lymphoid tissue) lymphoid tissues (Getty, 1975). The lymphoid system of chicken consists of unique organs and divided into two morphologically and functionally distinct components (Cooper et al., 1965, 1966). The thymusdependent component is represented by the smaller lymphocytes and is responsible for cell mediated immunity (CMI), including immunosurveillance (Janeyway et al., 1988), whereas, the bursa-dependent component is represented by the larger lymphocytes which transformed into plasma cell in the tissue and plays an important role in humoral immunity (HI). Concerning this immunological point of view, the histology of the lymphoid tissues of the chicken is very important. Although, the development, differentiation, histological observation in native chicken (Khalil Mohsin et al., 2002 \& 2003 and Rahman et al., 2003) and frequency of immunocompetent cells in the lymphoid tissues in Vencobb chicken (Karim et al., 2005) have been studied, however, regarding broiler, it is yet not to be done. Therefore, the present research has been carried out to understand the histological architecture of the lymphoid tissues of broilers. 


\section{MATERIALS AND METHODS}

\section{Chickens}

The study was carried out on fifteen 28-days-old "Kasilla" broilers of both sexes to study the topographic and histological structure of the lymphoid tissues (thymus, bursa, spleen and cecal tonsils) in the Department of Anatomy and Histology, Faculty of Veterinary Science, Bangladesh Agricultural University, Mymensingh during the period from October to December 2005. The birds had no developmental disorders and detectable disease that may cause any problem in the abnormalities of the histological architecture of lymphoid tissues.

\section{Tissues used for the study}

The birds were killed by cervical subluxation method and the thymus was collected by ventral neck dissection and bursa of Fabricius, spleen, cecal tonsils were collected through ventral abdominal dissection, which were free from pathological lesions.

\section{Preparation of tissues for histological study}

The tissues obtained from the chickens were fixed in the "Bouins fluid" (Gridley, 1960) for 24 hours and were dehydrated in the series of ascending grade of alcohol followed by clearing in three changes in xylene, and the tissues then infiltrated with different grades of melted paraffin in the oven. The tissues were then embedded in paraffin and finally the sections were cut at $6 \mu$ thickness using sliding microtome (MIC 509, Euromex, Japan). After cutting, the sections were floated on luke-warm water in a floatation bath at $37{ }^{\circ} \mathrm{C}$ for stretching and then the sections were mounted on clean slides using an adhesive (Egg albumins) and dried on a slide warmer at $37^{\circ} \mathrm{C}$. The sections were stained using Mayer's Hematoxylin and Eosin ( $\left.\mathrm{H} \& \mathrm{E}\right)$. The histological structures of the lymphoid tissues were observed using light microscope under low $(\times 10)$ and high $(\times 40)$ magnification. Photographs from the selected specimens were prepared for better illustration of the results. Then the measurements of different histological structures of the lymphoid tissues were performed by the calibrated stage micrometer in $\mu \mathrm{m}$ (micrometer).

\section{RESULTS AND DISCUSSION}

The thymus was a paired gland, one half of which was located on either side of the neck (Fig. 1a). Each half consisted of six to eight flattened pale white lobes of varying size of lymphoid tissue lying in the sub-dermal connective tissue of the neck region. The findings were similar to the report of King (1975), Hodges (1974) and Bach (1978) in the hybrid chickens. Histologically, it was enclosed by a thin connective tissue capsule. Numerous fine septa of connective tissue originated from the capsule and divided the organ into incompletely separated lobules. Each lobule organized into a peripheral cortex and a central medulla. The cortex stained more deeply basophilic than that of medulla (Fig. 2). Inside the medulla pale stained diffuse Hassall's corpuscles were found, which were arranged in a concentric formation. Using high power objective, presence of cords of lymphocytes was observed both in cortex and medulla. The histological architecture of the thymus in the present study is similar to the findings of King (1975) in White Leghorn chickens and Karim et al. (2005) in Vencobb chickens. The populations of lymphocytes in the cortex of the thymus in the present study were denser rather than that of medulla of the thymic lobule and were uniform in distribution (Fig. 2).

The bursa of Fabricius of chicken is a unique organ of the poultry for the production of B- lymphocytes. It was a blind, globular shaped, sac-like, dorsal diverticulum of the proctodeal wall of the cloaca (Fig. 1b). It was attached to the dorsal aspect of the proctodeum. This was in agreement with the available literatures of King (1975) and Hodges (1974). Histological observation revealed that, the bursa was consisted of long thick mucosal folds (plicae) which were projected into the lumen (Fig. 4). The middle region of the plica was thicker than the base and apical part. Numerous follicles filled the lamina propria of each fold. All the follicles had clear margin and they were separated from the adjacent lymphoid tissue by connective tissue fibers, cells and intercellular space. Each bursal follicle was composed a peripheral cortex and a central medulla (Fig. 3). A layer of undifferentiated epithelial cells occupied the periphery of the medulla, which was separated from the cortex by a capillary layer. The darkly stained cortex was composed of many closely packed small lymphocytes (Fig. 3). The paler medulla contained fewer cells of various sizes. 


\section{Lymphoid tissues of broilers}

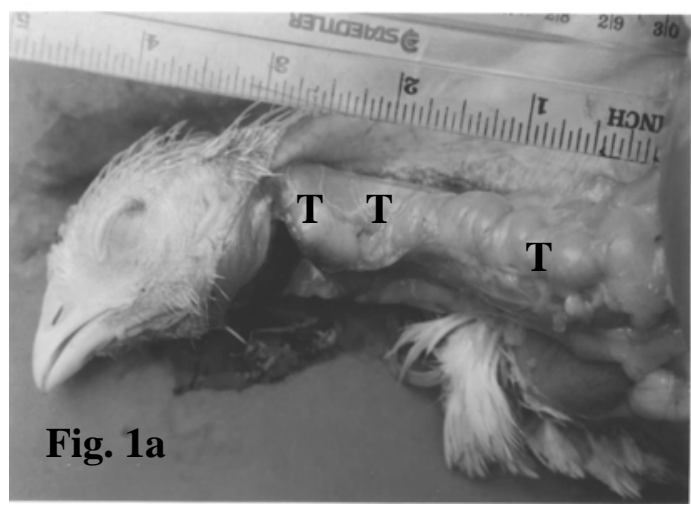

Fig. 1a. Gross photograph of the thymus (T) of broiler.

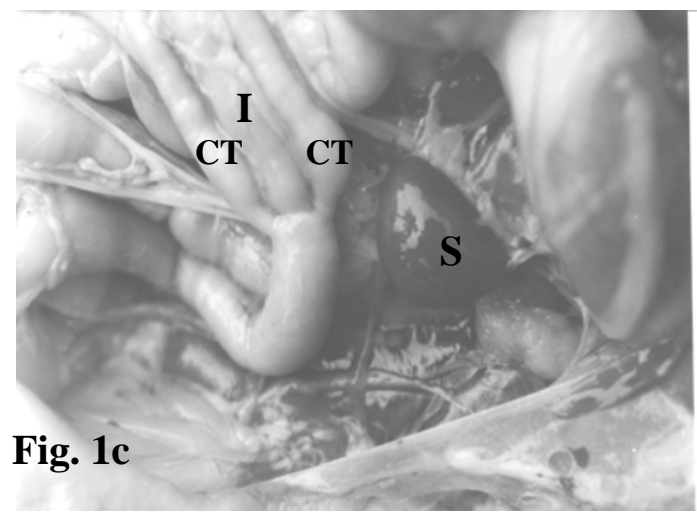

Fig. 1c. Gross photograph of the spleen $(\mathrm{S})$ and cecal tonsil (CT) of broiler.

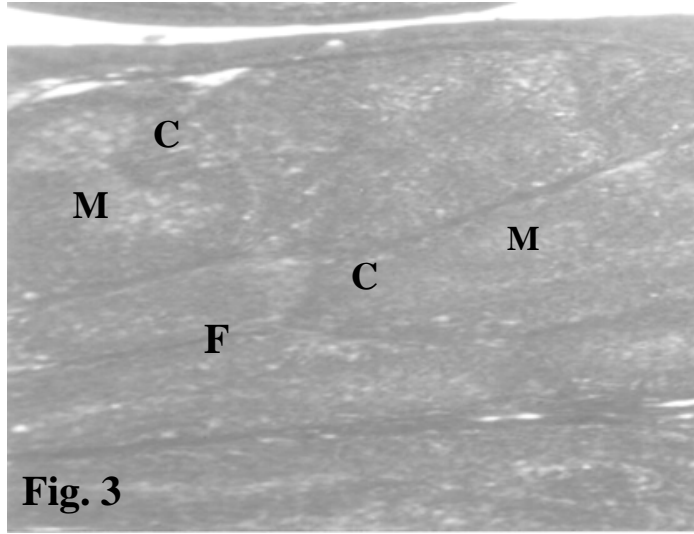

Fig. 3. Histological section of bursa of Fabricius of broiler. $\mathrm{H} \& \mathrm{E}$ stain, $\times 330, \mathrm{C}=$ Cortex, $\mathrm{M}=$ Medulla, $\mathrm{F}=$ Bursal follicle.

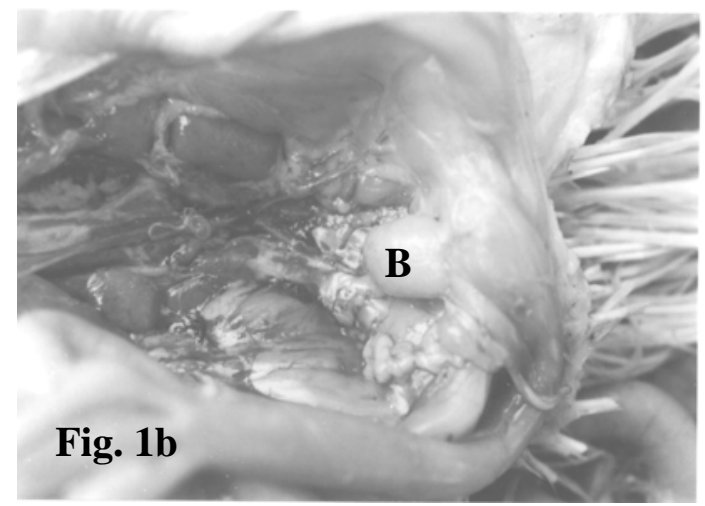

Fig. 1b. Gross photograph of the bursa of Fabricius (B) of broiler.

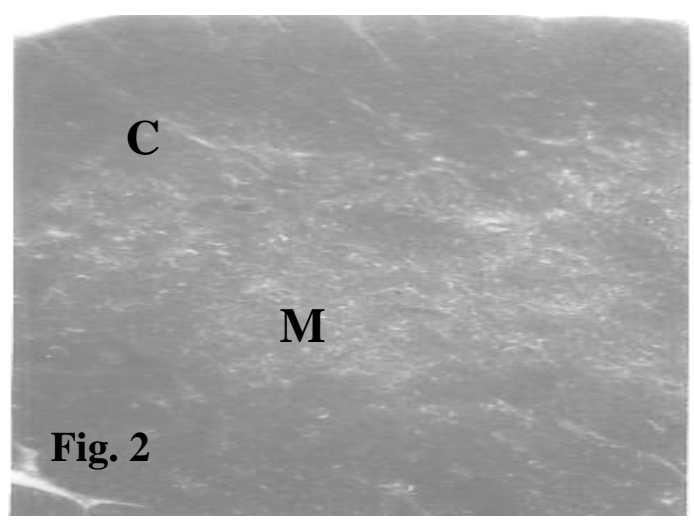

Fig. 2. Histological section of thymus of broiler. $\mathrm{H} \& \mathrm{E}$ stain, $\times 82.5, \mathrm{C}=$ Cortex, $\mathrm{M}=$ Medulla

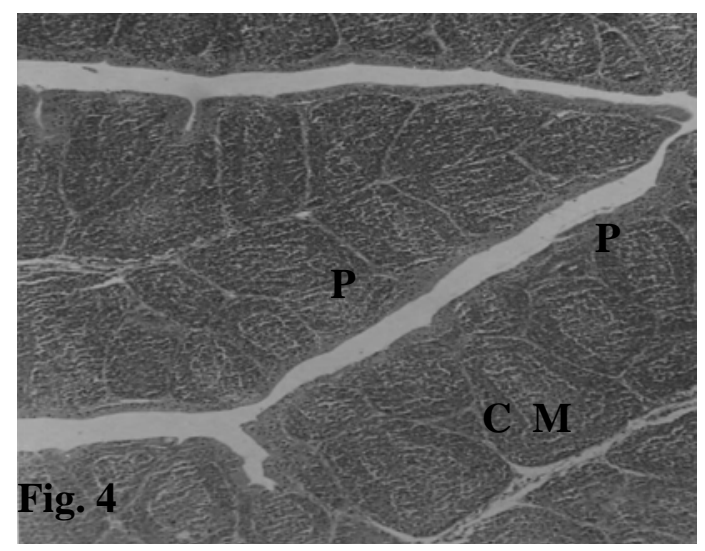

Fig. 4. Histological section of bursa of Fabricius of broiler. $\mathrm{H} \& \mathrm{E}$ stain, $\times 82.5, \mathrm{C}=$ Cortex, $\mathrm{M}=$ Medulla, $\mathrm{P}=$ Bursal plica. 


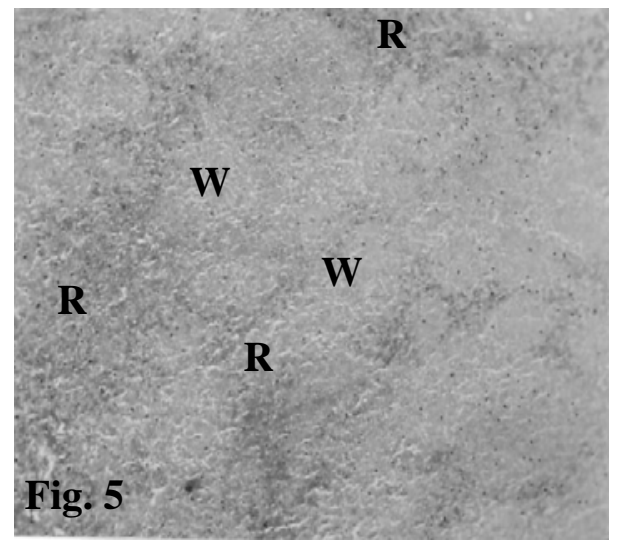

Fig. 5. Histological section of spleen of broiler. $\mathrm{H} \& \mathrm{E}$ stain, $\times 330, \mathrm{~W}=$ White pulp, $\mathrm{R}=$ Red pulp.

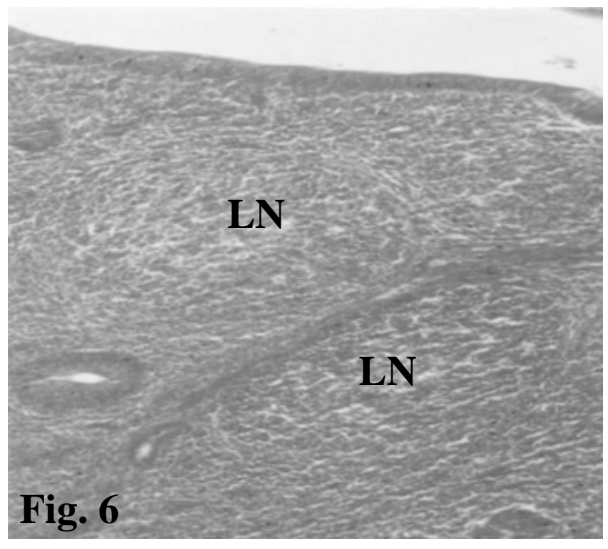

Fig. 6. Histological section of cecal tonsil of broiler. H \& E stain, $\times 330, \mathrm{LN}=$ Lymphatic nodule.

The mucosal fold of the bursa was lined by pseudostratified columnar epithelium, except at the apex of each follicle, which was covered by a simple columnar epithelium. The populations of lymphocytes were uniformly distributed and the periphery of the medulla was smooth and regular in appearance in the follicles of chickens. The findings are similar to the results made by Honjo and Hirota (1993) in germ free White Leghorn chickens and Khan et al. (1998) in Dekalb strain of White Leghorn.

The spleen was a rounded, reddish-brown organ which lies close to the right side of the junction between the proventriculus and gizzard (Fig. 1c). The findings are similar to the study of Hodges (1974). It was a mixed lymphoid tissue, having both the T- and B-cell zones. The spleen of the broiler was surrounded by a thick splenic capsule and there was a small number of trabeculi. The red pulps were less distinct and these were scatteredly distributed within the white pulp (Fig. 5). The white pulp was composed of network of reticular cells and reticular fibers within which small, medium and large sized lymphocytes and plasma cells were diffusely distributed. It contained sheathed arteries and lymphatic nodules. The red pulp of the spleen was formed from venous sinuses and anastomosing cord of reticular cells, macrophages, lymphocytes and blood cells. The network of the splenic tissue was consisted of a network of reticular cells and fibers. Histological structure of spleen of the present study in broiler is similar to the previous study as reported by Hodges (1974), King (1975) and Bach (1978).

Cecal tonsils were the most immunologically mature lymphoid organ. In the present study, it was found that the cecal tonsils were in the proximal one third of the paired tubular cecum, which laid along each side of the large intestine (Fig. 1c). They were broad tubular in shape. The shape of the cecal tonsils of broiler was similar to the report of King (1975) and Hodges (1974) in the hybrid chickens. It was composed of four histological layers i.e. tunica mucosa, submucosa, muscularis and serosa. Their lining epithelium was simple columnar epithelium. The bases of the mucosal folds (villi) were thick and the apexes were pointed or rounded in all groups of chickens in the present study. This report is in agreement with the Hodges (1974) in White Leghorn chickens and Khalil Mohsin et al. (2002 \& 2003) and Rahman et al. (2003) in native chicken. More diffuse lymphoid tissue and unorganized lymphatic nodules were present (Fig. 6) both in the mucosa and submucosa of the chickens.

The measurement by calibrated stage micrometer revealed that the length and breadth of the thymic lobules were $629.30 \pm 118.95 \mu \mathrm{m}$ and $376.03 \pm 98.92 \mu \mathrm{m}$, bursal follicles were $468.83 \pm 52.26 \mu \mathrm{m}$ and $240.70 \pm 34.19$ $\mu \mathrm{m}$, white pulp of the spleen were $112.62 \pm 13.25 \mu \mathrm{m}$ and $89.42 \pm 12.20 \mu \mathrm{m}$ and lymphatic nodules of the cecal tonsil were $255.20 \pm 20.46 \mu \mathrm{m}$ and $186.08 \pm 24.90 \mu \mathrm{m}$ respectively (Fig. 7). The results could not be compared due to unavailability of literature in this regard. 


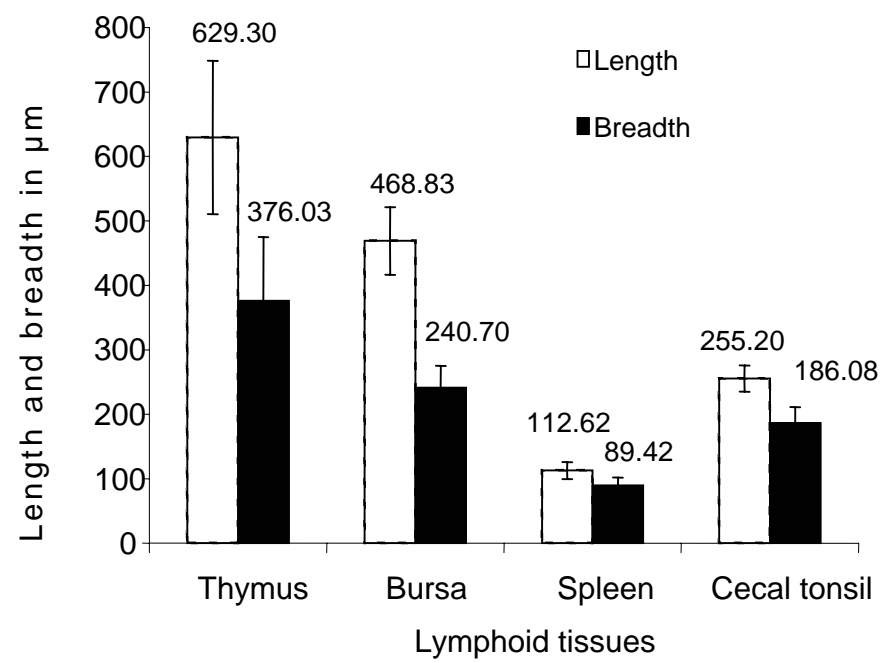

Fig. 7. The length and breadth of the thymic lobules, bursal follicles, white pulps of spleen and the lymphatic nodules of cecal tonsils.

It was revealed that the length and breadth of the thymic lobule was higher followed by bursal follicle, lymphatic nodule of the cecal tonsils and the white pulp of the spleen and the immunocompetent cells were arranged scatteredly or densely and as unorganized or organized lymphatic nodules in the lymphoid tissues. In conclusion, the results of the present study will be helpful to understand the changes in the frequency of the population of immunocompetent cells in drug induced, vitamin and mineral supplemented or hormone treated chickens in future.

\section{ACKNOWLEDGEMENT}

The Bangladesh Agricultural University Research System (BAURES), BAU, Mymensingh, Bangladesh is highly acknowledged for the provision of financial grant for this study.

\section{REFERENCES}

1. Bach JF (1978). Immunology. $5^{\text {th }}$ edn., John Wiley and Sons, New York, USA. pp. 15-35.

2. Cooper MD, Peterson RDA and Good RA (1965). Delineation of the thymic and bursal lymphoid systems in the chicken. Nature 205: 116-143.

3. Cooper MD, Peterson RDA, South MA and Good RA (1966). The functions of the thymus system and the bursa system in the chicken. Journal of Experimental Medicine 123: 75-102.

4. Getty R (1975). Sission and Grossman's The Anatomy of the Domestic Animal. $5^{\text {th }}$ edn., Vol. 2. W. B. Saunders Co., Philadelphia. London. pp. 2010-2018.

5. Gridley MF (1960). Manual of Histologic and Special Staining Technique. McGraw-Hill Book Company, INC, New York. pp. 28-29, 82-83.

6. Hodges RD (1974). The Histology of the Fowl. Academic Press, New York. pp 35-108.

7. Honjo K and Hirota Y (1993). Immunohistochemical investigations of lymphocytes in the lymphoid organs of cyclophosphamide treated chickens. Journal of Veterinary Medical Science 55: 895-897.

8. Janeyway CA, Jones B and Hayday A (1988). Specificity and function of T-cell bearing $\gamma \delta$ receptors. Immunology Today 9: 73-76. 
9. Karim MR, Khan MZI and Haque Z (2005). The dynamics of immunocompetent cells in the major lymphoid organs and mucosa associated lymphoid tissues of chemotherapy treated chickens. Journal of the Bangladesh Society for Agricultural Science and Technology 2: 5-8.

10. Khalil Mohsin, Islam ZI, Khalil Mansur and Islam R (2002). Effects of age in the structure of the bursa of Fabricius of deshi chicken of Bangladesh. Mymensingh Medical Journal 11: 91-93.

11. Khalil Mohsin, Islam ZI, Khalil Mansur and Islam R (2003). A prospective study of prenatal and postnatal development of thymus of deshi chicken. Mymensingh Medical Journal 12: 20-24.

12. Khan MZI, Hashimoto Y and Asaduzzaman M (1998). Development of T-cell sub-populations in postnatal chicken lymphoid organs. Vetrinarski Arhiv 68: 183-189.

13. Khan MZI, Hashimoto Y, Iwami Y and Iwanaga T (1997). Postnatal development of B-lymphocytes and immunoglobulin-continuing plasma cells in the chicken oviduct: studies on the cellular distribution and influence of sex hormones. Veterinary Immunology and Immunopathology 56: 329-338.

14. King AS (1975). Sisson and Grossman's The Anatomy of the Domestic Animals. Ed. by Getty R, 5th edn., Vol. 2., W. B. Saunders Co. Philadelphia, London. pp. 2010-2018.

15. Rahman ML, Islam MR, Asaduzzaman M and Khan MZI (2003). Lymphoid tissues in the digestive tract of Deshi Chicken (Gallus domesticus) in Bangladesh. Pakistan Journal of Biological Science 6: 1145-1150. 